\title{
Projeto Capacitar: Qualificação dos profissionais das creches filantrópicas e não-municipais de Viçosa-MG
}

Érica Aparecida Coelho ${ }^{1}$, Vivian Oliveira Tavares' ${ }^{2}$,Aurora Ribeiro de Goicochea ${ }^{3}$

RESUMO: As creches a cada dia têm recebido mais atenção da nossa sociedade, daí a importância dessas instituições possuírem profissionais capacitados. O Projeto Capacitar objetivou a capacitação e a qualificação de profissionais de creches filantrópicas e não-governamentais da cidade de Viçosa-MG. Durante sua atuação constatou-se alterações positivas em vários aspectos: maior integração entre os profissionais, maior envolvimento dos pais e da comunidade e mudanças na rotina institucional. Concluiu-se que seu objetivo foi alcançado e gerou melhoria na qualidade de vida das crianças atendidas pelas creches.

Palavras-chave: capacitação profissional, educação infantil, participação.

Área temática: Educação.

1 Graduanda em Economia Doméstica/UFV, bolsista PIBEX 2009 e 2010.

2 Graduanda em Economia Doméstica/UFV, bolsista PIBEX 2007 e 2008.

3 Professora do Departamento Economia Doméstica/UFV. 


\section{Project of training professional on education for daycare centers}

ABSTRACT: Daycare centers have received more attention in our society each day, hence the importance for these institutions to have trained professionals. The project Capacitar aimed to the training and qualification of professionals for philanthropic and non-government daycare centers in the city of Viçosa-MG. During the process, positive changes were found on several aspects. It was concluded that its objective was reached and a better quality of life for children served by day care centers was generated.

Keyword: job training, early childhood education, participation

Thematic area: education

\section{Proyecto de capacitación de profesionales para el trabajo en la educación de niños}

RESUMEN: Los centros de cuidados de día han recibido más atención en nuestra sociedad, de ahí la importancia de estas instituciones han capacitado a profesionales. El proyecto tenía como objetivo a la formación y cualificación de los profesionales de los centros de cuidado de ninos sin fines de lucro y no gubernamentales de la ciudad de Viçosa-MG. Durante su mandato se ha encontrado cambios positivos en varios aspectos. Se concluyó que su objetivo fue alcanzado y tuvo una mejor calidad de vida de los niños atendidos por las guarderías.

Palabras clave: capacitación para el trabajo, la educación infantil, la participación

Área temática: educación 


\section{INTRODUÇÃO}

A creche, a partir da Constituição de 1988, do Estatuto da Criança e do Adolescente e da Lei de Diretrizes e Bases da Educação, passou a ser concebida como direito da criança e um dever do Estado, o que implica em uma atuação, enquanto instituição educativa, responsável, juntamente com as famílias, pelo desenvolvimento da criança.

O cuidar passou a incluir também o educar; relacionando-se nesta perspectiva com o direito do brincar, de conviver num ambiente estimulante e aconchegante, de ter abrigo saudável, alimentação sadia, afeto e proteção na creche e em casa.

Nesse sentido, é importante se conceber a creche como uma instituição educativa que, por intermédio do trabalho do educador junto à criança, tenha a função de complementar o papel educativo da família (BOWLBY, 1969, citado por ROSEMBERG, 1989).

Refletir sobre o profissional de creche representa, por um lado, lidar com a visão e concepção que o mesmo constrói sobre a creche, a criança, sua família e seu trabalho. Por outro lado, significa encarar as dificuldades vivenciadas por ele, muitas vezes relacionadas ao desrespeito, à desvalorização, à precária ou à inexistente qualificação profissional, aos baixos salários e à ausência ou insuficiente interesse dos poderes públicos para com a creche (SILVA; MALAQUIAS et al. 2005).

Assim, assegurar a esses profissionais conhecimentos teóricos e práticos, para o avanço na escolaridade e o progresso na carreira, pode vir a ser importante alavanca para a tomada de consciência do seu lugar neste processo, assim como dos seus educandos. Isto não significa apenas um acúmulo de cursos, palestras e técnicas, mas um trabalho de reflexões críticas sobre as práticas e (re)construção permanente de uma identidade pessoal (NÓVOA, 1995, citado por SILVA; MALAQUIAS et al. 2005).

O trabalho na creche deve considerar a criança um ser social cooperativo e ativo na construção do seu conhecimento, cujo atendimento requer capacitação, atualização e valorização social dos profissionais. É importante apreender os valores e crenças dos profissionais sobre o ser criança, porque é em função deste que se constrói a prática e sobre a qual se produz reflexão e transformação (OLIVEIRA, 2001, citado por SILVA; MALAQUIAS et al. 2005).

Nesse contexto, assegurar um lugar de proteção à infância significa garantir um atendimento de qualidade, que se relaciona com o direito à igualdade e ao pleno exercício da cidadania. Para tanto, o 
ambiente físico e os profissionais encarregados de tais ações necessitam ser qualificados de forma continuada, a fim de que haja uma prática de cuidar e educar para assegurar a promoção da saúde e da higiene ambiental, pessoal e social, do crescimento e desenvolvimento integral da criança.

Para tanto, desde o ano de 2006 e a cada ano subsequente, a equipe executora do Projeto de Extensão Capacitar objetivou, em geral, capacitar os profissionais de duas creches filantrópicas e não-governamentais no município de Viçosa. Para tanto, especificamente pretendeu-se: discutir e oferecer apoio didático/pedagógico a todos os profissionais no que diz respeito ao conjunto de inter-relações que se estabelecem nas creches; refletir a ética profissional e o trabalho em cada uma das creches; estimular a conscientização quanto às questões ambientais; oferecer orientação quanto à utilização de materiais recicláveis como alternativa viável para a realização de atividades; promover a valorização da higiene ambiental, pessoal e social, com todos os envolvidos nas creches; aumentar as atividades de contação de histórias por meio da utilização de objetos alternativos; capacitar os prestadores de serviços de alimentação nas creches; introduzir a utilização de cardápios alternativos e de reaproveitamento de alimentos nas creches; buscar o fortalecimento da relação família/creche; estimular a autonomia das instituições atendidas pelo projeto, em relação às atividades a serem desenvolvidas.

\section{METODOLOGIA}

A partir de indicação de nove creches filantrópicas e não municipais pela Secretaria de Ação Social da Prefeitura Municipal de Viçosa, houve a certificação in loco da realidade dessas instituições, bem como foi construída a parceria entre os Programas de Educação Tutorial em Economia Doméstica (Grupo PET/ED) e em Administração (Grupo PET/ADM) e a Cace Consultoria Júnior (Empresa Júnior de Administração), todos da UFV; a fim de promover a melhoria dessas instituições, criando assim o "Programa Geração Criança", onde cada um dos grupos envolvidos participaria com projetos de adoção de creches.

Desde então, sob a coordenação de uma professora do Departamento de Economia Doméstica (DED/UFV), algumas bolsistas do Grupo PET/ED, juntamente com estudantes voluntárias do mesmo curso e uma bolsista de extensão integraram, a cada ano, a equipe executora do projeto. Nesta composição, os aspectos didáticos pedagógicos foram conduzidos por essa equipe e contando com a assessoria e colaboração de técnicas e professoras da área de Fa- 
mília e Desenvolvimento Humano do mesmo departamento e de profissionais de áreas afins.

Inicialmente, entre as nove creches apontadas pela Secretaria de Ação Social que foram adotadas pelo Programa Geração Criança, o projeto atuou em duas creches e buscou capacitar dirigentes, professores e demais funcionários para melhoria da qualidade do atendimento às crianças. Essa atuação se repetiu durante quatro anos consecutivos, conforme pré-diagnóstico realizado em cada creche.

O critério para a seleção das duas creches atendidas a cada ano compreendeu as necessidades de melhorias e investimentos. Também, considerou-se o desejo da creche em ser atendida pelo projeto.

$\mathrm{Na}$ fase de implantação do projeto em cada creche foi feito o Diagnóstico Rápido Participativo (DRP), acompanhado de entrevista semi-estruturada, observações e registros fotográficos, para planejar as atividades e maximizar a melhoria do atendimento. $\mathrm{O}$ DRP teve como objetivo discutir problemas e possíveis soluções para os mesmos, de forma coletiva e compromissada com o desenvolvimento integral das crianças. Sendo assim, a organização, a elaboração, a inclusão/exclusão de atividades e das temáticas e, ou práticas que foram trabalhadas nas creches foram orientadas por esse diagnóstico.

Assim, foram desenvolvidos trabalhos de orientação profissional e ética, relacionamento dinâmico e rotinas de atividades, bem como, orientações sobre contação de estórias, orientação sobre higiene (pessoal e social), capacitação sobre alimentação e confecção de brinquedos de sucata com materiais recicláveis. Tais atividades foram desenvolvidas por meio de palestras, mesas redondas e oficinas; elaboradas com linguagem fácil, clara e acessível ao público alvo.

Os colaboradores e parceiros do projeto a cada ano foram consultados sobre a continuidade em participar do projeto ou se indicariam substitutos. Estes seriam professores, técnicos do LDI (Laboratório de Desenvolvimento Infantil) e LDH (laboratório de Desenvolvimento Humano), estudantes estagiários da Ludoteca da UFV e outros que poderiam assessorar e, ou participar do projeto como voluntários e, ou colaboradores em certas atividades.

O acompanhamento e a avaliação do projeto envolveram a equipe executora e os profissionais das creches. $\mathrm{O}$ acompanhamento dos estudantes foi feito por meio da orientação da coordenadora e da elaboração de relatórios parciais e final a cada ano. 


\section{RESULTADOS E DISCUSSÕES}

Durante e após a atuação da equipe, foi possível constatar alterações positivas em vários aspectos relacionados às instituições. Destaca-se a reflexão por parte dos próprios funcionários sobre problemas vivenciados no cotidiano do trabalho e formas de superá-los. Isso proporcionou a criação de espaços para debates e reuniões entre eles, melhorias nas relações interpessoais e ética entre os profissionais, garantindo, dessa forma, um ambiente de trabalho mais harmonioso e cooperativo.

Notou-se que as atividades do Projeto Capacitar geraram satisfação para os coordenadores, os funcionários e as crianças, criando assim, momentos de descontração que contribuíam para o melhor entrosamento entre todos os envolvidos na instituição, incluindo os pais das crianças e a comunidade, que passaram a participar com maior interesse e assiduidade nas atividades desenvolvidas nas instituições.

As sugestões de adaptação dos cardápios das creches, incluindo novas preparações, com o reaproveitamento de alimentos, além da implementação de boas práticas de higiene durante todo o preparo e oferecimento dos alimentos, garantiram às crianças o consumo de alimentos mais nutritivos sem deixar de agradar à visão, ao olfato e ao paladar das mesmas, além de gerar economia.

A definição dos temas das palestras, mesas-redondas e oficinas de capacitação a partir das necessidades expostas pelos funcionários, permitiu a participação com maior satisfação e interesse. Dentre as atividades desenvolvidas, destacou-se a oficina de confecção de brinquedos utilizando sucatas (garrafa PET, caixas de leite, embalagens de iogurte, entre outros materiais), na qual foi trabalhada a conscientização ambiental sobre a questão do lixo, da degradação ambiental, da reutilização, do reaproveitamento e da reciclagem, e a importância de multiplicar tais conceitos de preservação ambiental para as crianças e a comunidade. Para se alcançar melhores resultados nesse aspecto, foi elaborada uma apostila de brinquedos de sucata, que foi entregue às instituições juntamente com demais materiais requisitados por elas.

Durante todo o trabalho desenvolvido nas instituições, salientou-se a importância de se trabalhar com a educação infantil, incentivando os funcionários a darem continuidade aos seus estudos, desenvolvendo neles uma maior valorização profissional e pessoal.

Foi identificada a pouca participação das famílias e da comunidade nas atividades das creches. Entretanto, no decorrer do andamento do projeto, com a realização de vários encontros e eventos 
nas creches, o envolvimento dos pais e da comunidade aumentou, com destaque para os movimentos de arrecadação de brinquedos e alimentos para as instituições.

\section{CONSIDERAÇÕES FINAIS}

Diante dos resultados alcançados, pode-se concluir que o Projeto Capacitar alcançou os objetivos propostos, gerando a capacitação e qualificação dos profissionais envolvidos nas nove_creches filantrópicas e não-municipais, trabalhadas de forma a fornecer aos profissionais o conhecimento para uma gestão autônoma, implicando na melhoria do atendimento oferecido pelas instituições e, consequentemente, melhorias na qualidade de vida das crianças; além do aumento do envolvimento dos pais e da comunidade no atendimento das necessidades vividas pelas instituições.

Atualmente, o Programa Geração Criança atende doze instituições, o projeto Capacitar já atuou em nove instituições de educação infantil filantrópicas e não-governamentais. Esse projeto está sendo continuado com a denominação de Projeto Renovar. 


\section{REFERÊNCIAS BIBLIOGRÁFICAS}

ROSEMBERG, F. Creche. São Paulo: Cortez, 1995. 251 p.

SILVA, M.S.; MALAQUIAS, T.G.; SILVA, L.B.; ALVES, M.F.P. Caracterização do Perfil dos Profissionais das Creches/ Pré-Escolas da Cidade do Recife - PE. In: CONGRESSO BRASILEIRO, 18; ENCONTRO LATINO-AMERICANO, 6; SIMPÓSIO ESTADUAL DE ECONOMIA DOMÉSTICA, 9, 2005, Francisco Beltrão. Anais... Francisco Beltrão: UNIOESTE/ABED, 2005. p.1- 13. 